DOI: 10.12731/2227-930X-2020-3-137-144

УДК 004.94

\title{
АЛГОРИТМИЗАЦИЯ \\ РАЦИОНАЛЬНОГО ИСПОЛЬЗОВАНИЯ РЕСУРСОВ В СИСТЕМЕ ПЕРЕВОЗОК
}

\section{Львович Я.Е., Преображенский А.П., Чопоров О.Н.}

В статье рассматривается задача, связанная с созданием алгоритма для рационального использования ресурсов в системе перевозок. Приведена математическая модель многошагового прочесса принятия решения по планированию перевозок. Дан частный случай алгоритма.

Ключевые слова: система перевозок; алгоритм; ресурс; управление.

\section{ALGORITHMIZATION OF RATIONAL USE OF RESOURCES IN THE TRANSPORTATION SYSTEM}

\section{Lvovich Ya.E., Preobrazhenskiy A.P., Choporov O.N.}

The paper considers the problem associated with the creation of an algorithm for the rational use of resources in the transportation system. A mathematical model of a multi-step decision-making process for transportation planning is presented. A special case of the algorithm is given.

Keywords: transportation system; algorithm; resource; control.

\section{Введение}

При управлении компаниями, связанными с перевозками могут быть использованы разные методы $[1,2]$. Они нацелены на то, чтобы было принято оптимальное решение. В общем виде математическая модель принятия оптимального решения может быть сформулиро- 
вана как задача нелинейного программирования. Эффективность численного решения подобной задачи оптимизации во многом определяется ее размерностью [3]. При одношаговом процессе принятия оптимального решения выбор численных значений для всех компонент вектора оптимизируемых переменных осуществляется одновременно, что при большой размерности анализируемой задачи может существенно затруднить поиск оптимального решения [4]. Одним из подходов к преодолению отмеченной трудности является организация процесса принятия решения в виде процесса, имеющего конечное число шагов [5]. В данной работе рассматривается алгоритм, позволяющий оптимальным образом использовать мощности компании, связанной с перевозками.

Алгоритм рационального использования производственных мощностей компании, связанной с перевозками. Предположим, что для некоторого участка компании, связанной с перевозками группу однотипных объектов задана соответствующая программа для каждого фиксированного периода времени (дня, недели, месяца), которая сильно меняется во времени (рис. 1). Обозначим через $m_{j}, j=\overline{1, N}$ плановое задание по перевозке объектов $[6,7]$ для $j$-го периода времени, а через $q_{j}=x_{j}, j=\overline{1, N}$ количество объектов практически перевозимых для $j$-го периода времени, что требует определенных затрат соответствующих ресурсов (техники, обслуживающего персонала, и т. д.). Потребуем, чтобы плановые задания $m_{j}$ всегда выполнялись:

$$
x_{j} \geq m_{j}, j=\overline{1, N} \text {. }
$$

Очевидно, что $x_{N+1}=x_{0}$ характеризует переходящий с предыдущего периода планирования объем перевозимых объектов. В том случае, когда производственные мощности можно использовать без всяких затрат оптимальный график перевозки объектов совпадает с плановыми заданиями:

$$
x_{i}^{*} \geq m_{j}^{*}, j=\overline{1, N} .
$$

Однако, если затраты по увеличению и сокращению производственных мощностей в каждый период времени значительны, то график перевозки объектов (рис. 1) может оказаться невыгодным 
с точки зрения общих затрат, связанных с рассматриваемыми процессами перевозок. В случае перевозки объектов больше планового задания $\left(x_{j}-m_{j}\right)$ приходится учитывать затраты, связанные с хранением этих объектов. Будем считать, что функция затрат, связанная с отклонением фактической перевозки объектов от плановых заданий имеет следующий вид:

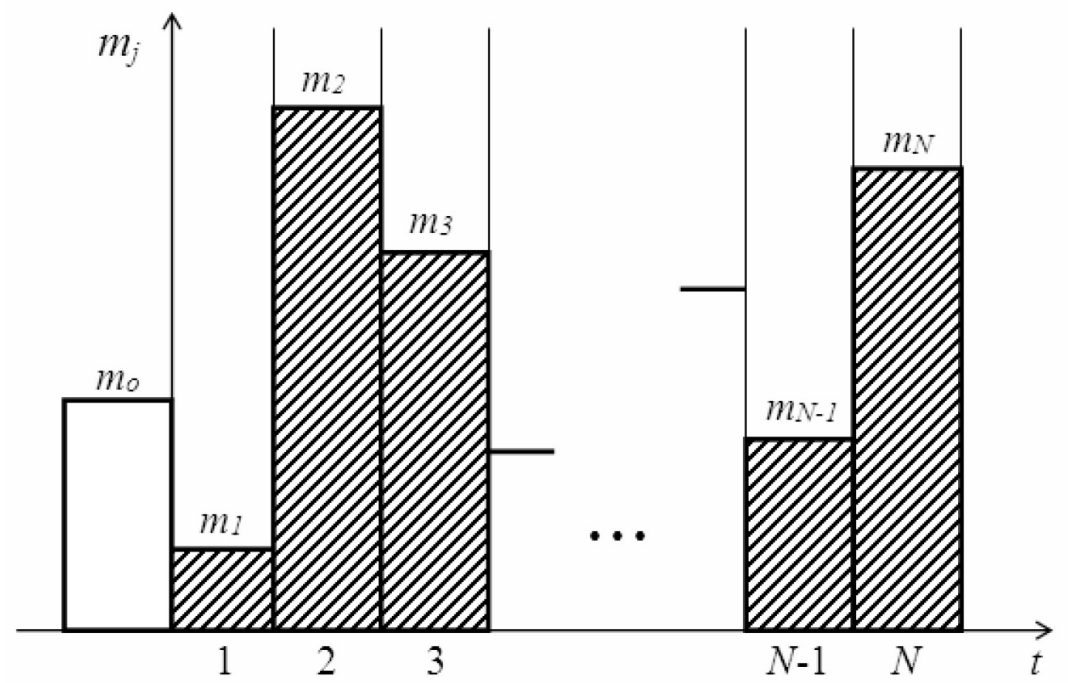

Рис. 1. Плановые задания $m_{j}$ по перевозке объектов в $j$-й период времени

$$
g_{j}\left(x_{j}-m_{j}\right)=\left\{\begin{array}{c}
0, \text { если } x_{j}=m_{j} ; \\
b_{j}\left(x_{j}-m_{j}\right)^{2} \text {, если } x_{j}>m_{j}
\end{array}\right.
$$

где $b_{j}>0, j=\overline{1, N}$ - стоимость хранения единицы объекта.

Кроме затрат, связанных с хранением объектов (3), необходимо учитывать затраты на изменение мощностей предприятия $[8,9]$, которые вызваны тем, что $x_{j} \neq x_{j+1}$ при переходе от $(j+1)$-го периода планирования к $j$-му периоду. Введем функцию $\varphi j\left(x_{j}-x_{j+1}\right)$ называемую функцией издержек сглаживания, которая характеризует затраты дополнительных средств [10] по введению в процессы перевозок новых мощностей: 
$\varphi j\left(x_{j}-x_{j+1}\right)=\left\{\begin{array}{c}0, \text { если } x_{j}=x_{j+1}(\text { мощности предприятия } \\ \text { не меняются), } \\ 0, \text { если } x_{j}<x_{j+1}(\text { затраты на уменьшение } \\ \text { мощностей предприятия равны нулю), } \\ a_{j}\left(x_{j}-x_{j+1}\right)^{2}, \text { если } x_{j}>x_{j+1} \text { (затраты, связанные с } \\ \text { увеличением мощностей предприятия, }\end{array}\right.$

где $a_{j}>0, j=\overline{1, N}$ - стоимость ввода единицы новых мощностей предприятия.

Математическая модель многошагового процесса принятия решения по количеству объектов, перевозимых в каждый период планирования $x_{j}^{*}, j=\overline{1, N}$, которые минимизируют суммарные затраты всего процесса перевозок, имеет следующий вид:

$$
\begin{aligned}
& F_{N}\left(x_{0}\right)=\min _{\substack{\left.x_{1}, \ldots, x_{N}\right) \\
x_{j} \geq m_{j} \\
j=1, N}}\left\{\sum_{i=1}^{N} q_{i}\left(x_{j}-m_{j}\right)+\varphi_{j}\left(x_{j}-x_{j+1}\right)\right\}= \\
& =\max _{\substack{\left(x_{1}, \ldots, x_{N}\right) \\
x_{j} \geq m_{j} \\
j=1, N}}\left\{\sum_{i=1}^{N} q_{i}\left(x_{j}-x_{j+1}\right)^{2}+B_{j}\left(x_{j}-m_{j}\right)^{2}\right\},
\end{aligned}
$$

где $x_{j}=0,1,2 \ldots-$ целые числа.

Решение сформулированной задачи может быть сведены к следующей системе одномерных задач оптимизации:

$$
f_{1}\left(p_{2}\right)=\min _{x_{1} \geq m_{1}}\left\{a_{1}\left(x_{i}-p_{2}\right)^{2}+B_{j}\left(x_{1}-m_{1}\right)^{2}\right\} ;
$$

$x_{1}$ - целое число

$$
\begin{gathered}
f_{k}\left(p_{k}+1\right)=\min _{x_{k} \geq m_{k}}\left\{a_{k}\left(x_{k}-p_{k+1}\right)^{2}+B_{k}\left(x_{k}-m_{k}\right)^{2}+f_{k-1}\left(p_{k}\right)\right\}, \\
k=\overline{2, N}
\end{gathered}
$$

Частный случай алгоритма. В частном случае, когда все $m_{j}$ $=0, j=\overline{1, N}$ (плановые задания на перевозку объектов отсутствуют), решение системы функциональных уравнений (6) - (7) сводится к следующей последовательности действий:

1. Определяется параметр:

$$
w_{1}=a_{1} b_{1} /\left(a_{1}+b_{1}\right) .
$$


2. По рекуррентному выражению вычисляется совокупность параметров:

$$
w_{k}=\left(a_{k} b_{k}+a_{k} w_{k-1}\right) /\left(a_{1}+b_{1}+w_{k-1}\right), k=\overline{2, N} .
$$

3. Вычисляется минимальное значение полных издержек процесса перевозок:

$$
f_{N}\left(x_{0}\right)=f_{N}\left(p_{N+1}\right)=w_{N} x_{0}^{2} .
$$

4. Определяется значение фактических перевозок объектов в $N$-й планируемый период:

$$
x_{N}^{*}=\frac{a_{N} p_{N+1}}{a_{N}+b_{N}+w_{N-1}} .
$$

5. По рекуррентному выражению вычисляется значения фактической перевозки объектов в каждом из планируемых периодов:

$$
x_{k}^{*}=\frac{a_{k} x_{k+1}}{a_{k}+b_{k}+w_{k-1}}, k=\overline{N-1,2} .
$$

6. Определяется перевозка объектов на шаге с номером «1»:

$$
x_{1}^{*}=a_{1} x_{2}^{*} /\left(a_{1}+b_{1}\right) \text {. }
$$

Решая последовательность одномерных задач оптимизации (6) - (7), получаем оптимальный план перевозки объектов $\left(x_{1}^{*}, \ldots, x_{N}^{*}\right)$, компоненты которого «близки» к плановым заданиям $\left(m_{1}, \ldots, m_{N}\right)$ и «мало» отличаются друг от друга с точки зрения полных затрат, связанных с организацией процесса перевозок.

\section{Выводы}

При рационализации ресурсов в системе перевозок можно использовать функцию затрат, а также математическую модель принятия решений. Кроме того, может потребоваться функция сглаживания. Если нет информации по плановым заданиям, может быть использован частный случай алгоритма.

Информация о конфликте интересов. Авторы заявляет об отсутствии конфликта интересов.

Информация о спонсорстве. Исследование не имело спонсорской поддержки. 


\section{Список литературы}

1. Паневин Р.Ю., Преображенский Ю.П. Задачи оптимального управления многостадийными технологическими процессами // Вестник Воронежского института высоких технологий. 2010. № 6. С. 77-80.

2. Преображенский Ю.П. Информационные технологии, используемые в сфере менеджмента // Вестник Воронежского института высоких технологий. 2018. № 2 (25). С. 43-46.

3. Ермолова В.В., Преображенский Ю.П. Методика построения семантической объектной модели // Вестник Воронежского института высоких технологий. 2012. № 9. С. 87-90.

4. Преображенский Ю.П., Коновалов В.М. Анализ подходов к формированию рекомендательных систем // Вестник Воронежского института высоких технологий. 2019. № 4 (31). С. 88-90.

5. Преображенский Ю.П., Коновалов В.М. О методах создания рекомендательных систем //Вестник Воронежского института высоких технологий. 2019. № 4 (31). С. 75-79.

6. Берман Н.Д., Белов А.М. Общественный транспорт и инновации // International Journal of Advanced Studies. 2019. T. 9. № 2. C. 7-13.

7. Шакиров А.А., Зарипова Р.С. Особенности моделирования логистических систем // International Journal of Advanced Studies. 2019. T. 9. № 4. C. 27-31.

8. Сапожникова С.М. Корпоративное управление в железнодорожном транспорте // International Journal of Advanced Studies. 2019. T. 9. № 4. С. 19-42.

9. Лысанов Д.М., Бикмухаметова Л.Т. Анализ показателей качества и конкурентоспособности оборудования // International Journal of Advanced Studies. 2018. T. 8. № 4-2. С. 50-55.

10. Преображенский Ю.П. Построение складской структуры предприятия // Молодежь и системная модернизация страны Сборник научных статей 3-й Международной научной конференции студентов и молодых ученых. В 4-х томах. Отв-й ред. А.А. Горохов. 2018. С. 286-290.

\section{References}

1. Panevin R.Yu., Preobrazhenskij Yu.P. Zadachi optimal'nogo upravleniya mnogostadijnymi tekhnologicheskimi processami // Vestnik Voronezhskogo instituta vysokih tekhnologij. 2010. № 6. S. 77-80. 
2. Preobrazhenskij Yu.P. Informacionnye tekhnologii, ispol'zuemye v sfere menedzhmenta // Vestnik Voronezhskogo instituta vysokih tekhnologij. 2018. № 2 (25). S. 43-46.

3. Ermolova V.V., Preobrazhenskij Yu.P. Metodika postroeniya semanticheskoj ob»ektnoj modeli // Vestnik Voronezhskogo instituta vysokih tekhnologij. 2012. № 9. S. 87-90.

4. Preobrazhenskij Yu.P., Konovalov V.M. Analiz podhodov k formirovaniyu rekomendatel'nyh sistem // Vestnik Voronezhskogo instituta vysokih tekhnologij. 2019. № 4 (31). S. 88-90.

5. Preobrazhenskij YU.P., Konovalov V.M. O metodah sozdaniya rekomendatel'nyh sistem //Vestnik Voronezhskogo instituta vysokih tekhnologij. 2019. № 4 (31). S. 75-79.

6. Berman N.D., Belov A.M. Obshchestvennyj transport i innovacii // International Journal of Advanced Studies. 2019. T. 9. № 2. S. 7-13.

7. Shakirov A.A., Zaripova R.S. Osobennosti modelirovaniya logisticheskih sistem // International Journal of Advanced Studies. 2019. T. 9. № 4. S. 27-31.

8. Sapozhnikova S.M. Korporativnoe upravlenie v zheleznodorozhnom transporte // International Journal of Advanced Studies. 2019. T. 9. № 4. S. 19-42.

9. Lysanov D.M., Bikmuhametova L.T. Analiz pokazatelej kachestva i konkurentosposobnosti oborudovaniya // International Journal of Advanced Studies. 2018. T. 8. № 4-2. S. 50-55.

10. Preobrazhenskij Yu.P. Postroenie skladskoj struktury predpriyatiya // Molodezh' i sistemnaya modernizaciya strany Sbornik nauchnyh statej 3-j Mezhdunarodnoj nauchnoj konferencii studentov i molodyh uchenyh. V 4-h tomah. Otvetstvennyj redaktor A.A. Gorohov. 2018. S. 286-290.

\section{ДАННЫЕ ОБ АВТОРАХ}

Львович Яков Евсеевич, профессор, доктор технических наук, профессор

Федеральное государственное образовательное учреждение выстего образования Воронежский государственный технический университет

ул. 20 лет Октября, 84, г. Воронеж, 394006, Россия Komkovvivt@yandex.ru 
Преображенский Андрей Петрович, профессор, доктор технических наук, доцент

Автономная некоммерческая образовательная организация высшего образования Воронежский институт высоких технологий ул. Ленина, 73а, Воронеж, 394043, Россия Komkovvivt@yandex.ru

Чопоров Олег Николаевич, профессор, доктор технических наук, профессор

Федеральное государственное образовательное учреждение высшего образования Воронежский государственный технический университет

ул. 20 лет Октября, 84, г. Воронеж, 394006, Россия Komkovvivt@yandex.ru

\section{DATA ABOUT THE AUTHORS}

Lvovich Yakov Yevseevich, Professor, doctor of technical Sciences, Professor

Voronezh State Technical University

84, 20 years of October Str., Voronezh, 394006, Russia

Komkovvivt@yandex.ru

ORCID: 0000-0002-7051-3763

Preobrazhenskiy Andrey Petrovich, professor, doctor of technical sciences, associate professor

Voronezh Institute of High Technologies

73a, Lenin Str., Voronezh, 394043, Russia

Komkovvivt@yandex.ru

ORCID: 0000-0002-6911-8053

Choporov Oleg Nikolaevich, Professor, doctor of technical Sciences, Professor

Voronezh state technical University

84, 20 years of October Str., Voronezh, 394006, Russia

Komkovvivt@yandex.ru

ORCID: 0000-0002-3176-499X 